\title{
ORIGENS DO FÓRUM MINEIRO DE SAÚDE MENTAL: UM ESTUDO SOBRE AS CONDIÇÕES DE EMERGÊNCIA DE UM MOVIMENTO SOCIAL ANTIMANICOMIAL
}

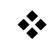 \\ Ronaldo Alves Duarte \\ Universidade Federal Fluminense - UFF - Brasil \\ $*$
}

\begin{abstract}
Resumo
Este artigo objetiva identificar e sistematizar as condições de emergência do Fórum Mineiro de Saúde Mental, considerando aspectos políticos, sociais e econômicos ocorridos entre os anos de 1987 e 1994, e identificando seus efeitos, influências e reverberações sobre a formação do FMSM. Para tanto, a investigação conjugou informações oriundas de fontes orais, escritas e documentais acerca do painel de eventos sociais, políticos, econômicos e culturais da conjuntura mineira em que surgiu o Fórum Mineiro de Saúde Mental. Tudo isso refletido em uma perspectiva de análise conjuntural. Constatou-se que o FMSM não se manteve isolado nem imune aos efeitos da conjuntura política, social, econômica e cultural do período aqui enfocado. Assim, forjado em um processo complexo de aceitação e de resistências, o Fórum Mineiro de Saúde Mental se materializou em Minas Gerais, pretendendo tornar as aspirações antimanicomiais uma realidade no Estado.
\end{abstract}

Palavras-chave: movimento antimanicomial. reforma psiquiátrica. movimentos sociais.

\section{Introdução}

A emergência do Movimento Antimanicomial brasileiro, já na condição de movimento social propriamente dito, data de 1987, quando foi realizado, na cidade de Bauru/SP, o II Congresso de Trabalhadores de Saúde Mental. Estabelecendo a data de 18 de maio como dia nacional da luta antimanicomial, criando o lema: Por uma Sociedade Sem Manicômios! e propondo uma aproximação com as associações de usuários e familiares, o Movimento Antimanicomial desencadeou um processo de expansão do fazer da política pública de saúde mental para o domínio dos vários atores sociais e para as diversas dimensões da vida social.

Desde o Congresso de Bauru, "diversos núcleos de militância do Movimento foram se formando nos serviços, em articulações municipais, regionais e estaduais em todo o Brasil" (VASCONCELOS, 2007, p. 187). Assim, desde o início dos anos 1990, embora ainda sem uma organicidade interna e com seus núcleos dispersos pelo território nacional, o Movimento Antimanicomial já buscava transformar as práticas em saúde mental objetivando a criação de 
um modelo assistencial mais inclusivo e composto por uma rede de serviços de base comunitária que substituísse o tradicional modelo centrado no hospital psiquiátrico.

Atualmente existe um acervo considerável de trabalhos acadêmicos que versam sobre o Movimento Nacional Antimanicomial, entretanto, observa-se uma grande lacuna quando se trata de trabalhos de investigação que se debrucem sobre a especificidade dos núcleos antimanicomiais. Nestes termos, objetiva-se no presente trabalho, identificar e sistematizar as condições de emergência do Fórum Mineiro de Saúde Mental (FMSM) considerando aspectos políticos, sociais e econômicos ocorridos entre os anos de 1987 e 1994, identificando seus efeitos, influências e reverberações sobre o FMSM.

O Fórum foi o primeiro Núcleo do Movimento Antimanicomial a se formar em território mineiro. Trata-se de um coletivo em atividade há mais de vinte anos, constituído predominantemente por usuários, seus familiares e trabalhadores de serviços de saúde mental. O FMSM vem se destacando desde o início dos anos 1990 na luta pela ampliação dos direitos do portador de transtorno mental e pela melhoria da política de saúde mental mineira, sobretudo em Belo Horizonte e sua região metropolitana. Assim, uma pesquisa que se detenha sobre o FMSM como objeto de estudo, identificando e sistematizando as condições de emergência dele tem uma importância muito grande no sentido de resgatar uma memória, que entre outras coisas pode dar mais sentido às lutas atuais do Movimento.

Optou-se por delimitar a presente investigação a uma temporalidade inscrita entre os anos de 1987 e 1994, dada a necessidade de abordar as condições históricas, sociais e políticas que culminaram na emergência de um movimento social como o Fórum Mineiro de Saúde Mental. A escolha desse período justifica-se por ser 1987 o ano de fundação do Movimento Nacional Antimanicomial e o ano de 1994 a constituição jurídica do FMSM. Com o desenvolver da pesquisa, no entanto, surgiu a necessidade de se retroceder a momentos históricos anteriores aos inicialmente estabelecidos, uma vez que a origem de muitas questões relacionadas à saúde mental brasileira atual está em eventos que remontam sobretudo às décadas de 1970 e 1980. Nestes termos, empreendeu-se uma construção de uma discussão de ordem histórica, destacando os elementos conjunturais e o campo de forças presentes na configuração da luta antimanicomial mineira.

Caracterizado como uma narrativa histórica acerca das condições de emergência do FMSM, a coleta de dados para o presente trabalho, em um primeiro momento, consistiu na leitura analítica de documentos e de produções bibliográficas diversas que possibilitasse construir um percurso histórico de acontecimentos alicerçado em um diálogo com documentos, textos, opiniões e posicionamentos de autores já consagrados no campo da saúde 
mental. Em um segundo momento, coletou-se informações por meio de uma pesquisa empírica, na qual se utilizou como instrumento de coleta de dados a entrevista não estruturada. Essa entrevista possibilitou a apreensão de depoimentos que revelassem dados e fatos capazes de reconstituir historiograficamente o contexto de surgimento do FMSM. Essas entrevistas foram registradas em gravador eletrônico, e posteriormente transcritas.

Por meio da frequência a reuniões ordinárias do Fórum Mineiro de Saúde Mental estabeleceu-se contatos com lideranças do FMSM, as quais indicaram alguns nomes de pessoas fortemente ligadas à área da saúde mental em Minas Gerais. Desse modo, foi possível estabelecer a inclusão dos primeiros sujeitos colaboradores da presente pesquisa: alguns militantes que participaram do FMSM desde a sua fundação. A partir desse contato com esses primeiros sujeitos e por indicação deles, foram incluídos, entre os colaboradores, também pessoas que embora não estivessem frequentando o FMSM naquele momento, testemunharam o surgimento e parte da evolução desse movimento social. A esse grupo de colaboradores, somou-se, ainda, um outro sujeito de pesquisa que, mesmo não tendo atuado diretamente no FMSM, viveu a conjuntura histórica, política e social retratada neste trabalho, o que justificou sua inclusão no grupo.

O contato entre o pesquisador e os sujeitos de pesquisa ocorreu pessoalmente, oportunizando explicar a cada um deles os objetivos da pesquisa e as expectativas em relação à participação de cada informante. Buscando manter o anonimato dos sujeitos de pesquisa, os mesmos não terão seus nomes verdadeiros grafados no texto deste artigo. Assim sendo, adotou-se a estratégia de identificar o depoimento de cada entrevistado por um nome fictício, sendo eles: Alba, Gisele, Francisca e Renata ${ }^{1}$.

No que diz respeito à análise dos dados, as informações, coletadas por meio das entrevistas não estruturadas, foram organizadas e categorizadas de acordo com evidências factuais e cronológicas que possibilitaram remontar a história do contexto de surgimento do FMSM no período estudado. Essa reconstituição histórica, feita primeiramente por meio da pesquisa empírica, foi, em seguida, articulada às informações referentes aos fatos históricos já registrados por autores ou mesmo pelos documentos consultados. Isso permitiu uma construção de uma trajetória histórica do passado, de modo que as fontes orais, por vezes, preencheram espaços vazios ou contextos pouco explorados pelos documentos consultados.

\footnotetext{
${ }^{1}$ Todos os sujeitos foram entrevistados na cidade de Belo Horizonte, entretanto, os locais exatos, bem como os horários em que as entrevistas foram realizadas foram definidos por cada um dos sujeitos da pesquisa. Em relação às datas, elas ficaram assim definidas: Alba (13/10/2013), Gisele (13/11/2013 e 06/02/2014), Francisca (26/11/2013 e 05/02/2014) e Renata (17/02/2014).
} 
Considerando "a importância do contexto econômico, político e social mais amplo em qualquer processo de reforma psiquiátrica" (VASCONCELOS, 2008, p. 52), todas as informações oriundas das fontes orais e escritas foram trabalhadas em uma perspectiva conjuntural, buscando compreender as inter-relações dos fatos políticos, sociais, econômicos e culturais que teceram as condições de emergência do Fórum Mineiro de Saúde Mental.

\section{1 - Antecedentes históricos e políticos à militância antimanicomial mineira}

Seguindo o fluxo da política de saúde mental adotada pela federação, o Estado de Minas Gerais repetiu, sobretudo a partir da década de 1960, a tendência a uma progressiva privatização da assistência psiquiátrica, materializada pela inauguração crescente de hospitais psiquiátricos particulares. Esse contexto permitiu que se reproduzisse, também no território mineiro, a combinação da exploração comercial da loucura, com a coisificação do louco, em nome do lucro, tal qual verificado em outras partes do país. Isso se tornou, a partir da década de 1970, objeto de questionamentos e críticas severas feitas por parte da opinião pública, momento em que Minas Gerais teve papel impulsionador da Reforma Psiquiátrica brasileira, dado o fato de serem levadas ao conhecimento da sociedade as péssimas condições de atendimento oferecidas, à época, à pessoa com transtorno mental no Estado.

Diferentemente do Rio de Janeiro, onde a crise da Divisão Nacional de Saúde Mental teve um forte impacto impulsionando a Reforma Psiquiátrica (AMARANTE, 1998), no caso de Minas Gerais, a mola propulsora da Reforma Psiquiátrica foram as estratégias de denúncias que possibilitaram a problematização das questões relativas à saúde mental não só no território mineiro, mas também em todo o país. Desse modo, em 1979, em Minas Gerais, promovendo uma interlocução com a bem-sucedida experiência italiana de psiquiatria democrática, realizou-se o III Congresso Mineiro de Psiquiatria, o qual contou com a participação de usuários, seus familiares, jornalistas e especialistas em saúde mental como Franco Basaglia e Robert Castel. Este evento conseguiu atingir a opinião pública de todo o país, ao ampliar as discussões acerca dos problemas enfrentados pela saúde mental para além dos domínios exclusivos dos técnicos e profissionais da área da saúde (AMARANTE, 1998; MINAS GERAIS, 2007).

Ao ir até Minas Gerais para participar do III Congresso Mineiro de Psiquiatria, Basaglia teve a oportunidade de conhecer pessoalmente, entre outras instituições psiquiátricas, o Hospital Colônia de Barbacena, fazendo com que a precária assistência psiquiátrica de Minas Gerais ganhasse repercussão nacional e internacional. Assim, as 
declarações do renomado psiquiatra italiano a respeito do hospício de Barbacena, comparando-o a um campo de concentração nazista, "garantiu visibilidade mundial ao tema da loucura e à forma como vinha sendo tratada em Minas Gerais. [...] Até o New York times se interessou pela tragédia da loucura mineira.” (ARBEX, 2013, p. 206-207).

No âmbito das discussões acerca da política nacional de saúde mental, as propostas debatidas no evento causaram considerável impacto positivo. A partir das propostas foi elaborado um documento que acabou por influenciar decisões do governo federal em sua tentativa de reorganizar a saúde mental em nível nacional. Desse modo, o Programa de Reorientação da Assistência Psiquiátrica Previdenciária (PRAPP), por exemplo, foi inspirado nas proposições debatidas no III Congresso Mineiro de Psiquiatria (GOULART, 2011).

Nesse mesmo ano de 1979, foram divulgadas duas denúncias que também mobilizaram a opinião pública em todo o Brasil. Uma delas foi composta pelas reportagens intituladas Nos porões da loucura, do jornalista Hiram Firmino, no Jornal Estado de Minas. E a outra, de formato cinematográfico, foi o filme Em nome da Razão, de autoria do cineasta Helvécio Ratton. Ambas as denúncias foram produções mineiras e expunham a face horrenda do hospital psiquiátrico, além de tornar públicas as condições subumanas em que eram tratados os internos.

Como consequência disso, o então recém-criado Movimento dos Trabalhadores em Saúde Mental (MTSM) buscou apresentar, para toda a sociedade, a problemática vivenciada pelos portadores de transtorno mental, instaurando-se, a partir de então, "uma série de debates e seminários sobre a realidade do que acontecia dentro das instituições manicomiais. Era preciso modificar, [...] e humanizar os hospitais psiquiátricos" (SOUZA, 2002, p. 40).

É nesse contexto que a Reforma Psiquiátrica em Minas Gerais deu os seus primeiros passos. Nestes termos, a recém-criada Associação Mineira de Saúde Mental

\footnotetext{
ganhou força, abrindo as portas para os militantes 'basaglianos' [...]. Pressionada, a Fundação Hospitalar do Estado de Minas Gerais (FHEMIG), que passou a gerir a totalidade dos hospitais públicos do estado em 1977, período em que as antigas fundações de assistência de saúde do Estado se fundiram, aprovou em 1980, o Projeto de Reestruturação da Assistência Psiquiátrica, que acolheu as teses do III Congresso Mineiro de Psiquiatria. As mudanças foram sentidas no Instituto Raul Soares e posteriormente se estenderam ao Hospital Galba Veloso, Centro Psicopedagógico (ex-hospital de Neuropsiquiatria infantil) e Centro Hospitalar Psiquiátrico de Barbacena (ex-hospital Colônia de Barbacena). Os porões da loucura, finalmente começaram a ser abertos (ARBEX, 2013, p. 209-210).
}

Corroborando com esse processo, a redemocratização política em curso já no início dos anos 1980, tal qual em outros estados brasileiros, possibilitou que Minas Gerais elegesse um governo democrático, liderado por Tancredo Neves. Este governo permitiu a expansão das 
possibilidades de participação da sociedade civil em questões antes exclusivas da máquina pública. Essa favorável conjuntura política viabilizou a entrada de militantes dos movimentos pela Reforma Sanitária e pela Reforma Psiquiátrica no aparelho do Estado, tanto no nível municipal, quanto no estadual. Foi possível, assim, que os trabalhadores mineiros envolvidos com a causa da Reforma Psiquiátrica propusessem e implementassem ações no campo da saúde mental, fazendo com que diversas mudanças ocorressem nesta política.

No que diz respeito à ampliação da saúde mental no nível ambulatorial, por exemplo, essas mudanças se deram na perspectiva das Ações Integradas de Saúde (AIS), visando o fortalecimento de um sistema de saúde unificado e descentralizado, focado, sobretudo, em ações integrais que fossem capazes de superar as dicotomias preventivo/curativo, individual/coletivo, ambulatorial/hospitalar. Assim, foram constituídas equipes multiprofissionais compostas por psicólogos, assistentes sociais e psiquiatras. Nestes termos, em Belo Horizonte e sua região metropolitana foram

\begin{abstract}
apresentadas 23 equipes de Saúde Mental divididas em 18 centros de saúde e em cinco unidades de serviços de pronto atendimento e da rede hospitalar, em parceria com algumas prefeituras.[...] A princípio, o Programa de Saúde Mental buscava formular, de modo ainda primário, uma concepção integral de saúde - o famoso trinômio do bio-psico-social. Por isso, as primeiras equipes de Saúde Mental respeitavam essa conformação: psiquiatria (bio), psicólogo (psico) e assistente social (social) (NETO, 2008, p. 20).
\end{abstract}

Essas equipes atuavam nas unidades básicas de saúde objetivando, principalmente, evitar que o paciente psiquiátrico chegasse à internação hospitalar. No caso daquele paciente que não fosse possível evitar sua internação, o papel da equipe se concentrava em assisti-lo fora dos domínios do hospital, quando de sua alta hospitalar.

Desse modo, o Programa de Ações de Saúde Mental desenvolvido com a implantação dos serviços ambulatoriais em algumas cidades mineiras teve uma importância capital para o movimento da Reforma Psiquiátrica no Estado. Isso porque o Programa ousou introduzir modificações na lógica do tratamento oferecido ao louco vigente no Brasil desde o século XIX, possibilitando a quebra da hegemonia do saber psiquiátrico como único e absoluto no cuidado para com a pessoa com transtorno mental. Assim, a ampliação da quantidade de serviços ambulatoriais no estado de Minas Gerais demandou um enorme contingente de trabalhadores para compor as equipes multiprofissionais em saúde. Houve então, a contratação, por meio de concurso público realizado pela Fundação Hospitalar do Estado de Minas Gerais (FHEMIG), de milhares de profissionais não-médicos nos diversos serviços de saúde. Conforme afirma uma entrevistada, "o concurso da FHEMIG foi para cerca de 1300 
vagas espalhadas em equipes profissionais em Minas inteira, principalmente na atenção básica" (ALBA).

Muitos dos profissionais admitidos neste contexto acabaram por ter contato, pela primeira vez, com as ideias defendidas pelos movimentos das Reformas Psiquiátrica e Sanitária que vinham acontecendo no Brasil desde o final da década de 1970. Isso fez com que centenas desses profissionais se simpatizassem com os ideais dessas reformas, tornandose militantes do movimento em favor do redirecionamento da política de saúde mental em Minas Gerais. O depoimento a seguir expressa com clareza essa questão:

\begin{abstract}
Logo que eu entrei na saúde pública, em 1986, eu já fui me inteirando dos problemas que tinham no campo da saúde, tomei conhecimento que tinha acabado de acontecer a VIII Conferência Nacional de Saúde, que aconteceu no mês de junho de 1986. Soube que tinha tido uma grande mobilização política para essa VIII Conferência, fiquei sabendo que ali foram traçadas as diretrizes da construção do Sistema Único de Saúde. E aí eu fui tomando conhecimento de que no campo da saúde mental, já havia acontecido, desde o final dos anos 1970, alguns movimentos de trabalhadores. [...] Eu fiquei sabendo que tinha acontecido o III Congresso Mineiro de Psiquiatria em 1978 e que o Basaglia tinha vindo aqui em Minas. [...] Fui me inteirando e fui me aproximando dos Sindicatos dos Psicólogos e do Conselho de Psicologia. Inicialmente, eu fui trabalhar em uma comissão de saúde dos psicólogos do Conselho. [...] Foi nesta comissão de saúde que começamos a discutir o papel e a função dos psicólogos dentro da saúde mental; a entender um pouco da realidade, da assistência à saúde mental. [...] E aí nós fomos nos preparar para participar em 1987 da primeira Conferência Nacional de Saúde Mental, que aconteceu no Rio de Janeiro [...] (FRANCISCA).
\end{abstract}

Este depoimento permite destacar que as ações em saúde mental desenvolvidas na rede ambulatorial nas diversas cidades mineiras, sobretudo em Belo Horizonte e sua região metropolitana, foram fundamentais para possibilitar a centenas de profissionais um acesso a experiências práticas e a diversas informações acerca de tudo aquilo que sustentava a luta pela Reforma Psiquiátrica. Além disso, o Programa proporcionou a esses profissionais fazerem parte "do que foi a primeira geração, em Minas Gerais, que pôde experimentar, ainda que sem muito sucesso com as psicoses e suas crises, uma intenção de oferecer cuidados extrahospitalares ao sofrimento mental” (SILVA, 2013, p.02).

As tentativas de humanização dos hospitais psiquiátricos bem como a ampliação dos serviços ambulatoriais vinham se configurando em Minas Gerais como uma importantíssima estratégia para reorientar a assistência psiquiátrica. Entretanto, uma radical mudança na conjuntura política no Governo do estado, fez desacelerar abruptamente os avanços experimentados pela política de saúde mental na gestão Tancredo Neves/Hélio Garcia. Nesse contexto, em 1987, a eleição de Newton Cardoso (PMDB) para governador "transformou-se no maior obstáculo para avanços da saúde pública no Estado de Minas Gerais. Com isso, esse 
setor passou a sofrer uma variação radical, em comparação ao período Tancredo/Hélio e até aos governos da ditadura" (PEREIRA, 2004, p. 287). O governo de Newton Cardoso, além de fechar o espaço político em Minas Gerais, representou um enorme retrocesso para as políticas públicas como um todo. No caso da saúde mental, diversos militantes que atuavam junto ao governo progressista na gestão anterior sofreram perseguições políticas e foram demitidos.

Somou-se a esse retrocesso no âmbito político, o fato de que as ações empreendidas pelo Programa de Saúde Mental não obtiveram o sucesso esperado. Desse modo, a tentativa de humanizar o hospício só chegou até onde a forte cultura manicomial dominante à época permitiu. O trabalho previsto pelo Programa de Ações em Saúde Mental não alcançou as redes de leitos psiquiátricos conveniadas, deixando sem qualquer controle do Estado tanto a indicação quanto a qualidade do tratamento realizado nessas instituições privadas. Além disso, as equipes multiprofissionais de saúde mental que atuavam dentro dos hospitais psiquiátricos públicos também enfrentavam problemas (SILVA, 2013; LOBOSQUE, 1997).

Nesse contexto, também as ações em saúde mental na atenção primária não lograram o êxito esperado. Exemplo disso foi que o principal objetivo de refrear as internações hospitalares, interceptando o fluxo que fazia conexão direta entre o paciente e o manicômio, não havia sido alcançado. Conforme informa o depoimento a seguir, a falta de êxito do Programa de Saúde Mental implantado em Minas Gerais pode ser compreendida a partir de uma série de fatores: 1) a implantação das equipes de saúde mental não ocorreu na totalidade dos municípios do Estado, e, onde ocorreu, não conseguiu cobrir todas as unidades de saúde existentes; 2) a oferta de ações em saúde mental pôs luz sobre uma demanda reprimida por esse tipo de serviço por um público não previsto pelo programa, sobrecarregando os profissionais e comprometendo o atendimento ao público-alvo do programa (o egresso do hospital psiquiátrico); 3) a não-aderência dos donos de hospitais psiquiátricos, boicotando o encaminhamento do paciente de alta hospitalar para as unidades básicas de saúde.

O programa criado pelo Estado era para atender ao portador de sofrimento mental
grave, aos psicóticos egressos dos hospitais psiquiátricos. Eles [pacientes] tinham
uma crise aí eram internados. Quando saíssem, eles deviam continuar o tratamento
nas unidades básicas de saúde. O Problema é que isso não aconteceu ou aconteceu
de uma maneira muito espaçada, fragmentada. Isso porque, primeiro, quando foram
constituídas as equipes mínimas de saúde mental em unidades básicas de saúde, isso
só ocorreu em algumas unidades, só nas cidades maiores do Estado de Minas Gerais
[...]. Além disso, os profissionais encontraram uma demanda enorme de pessoas que
demandavam saúde mental, mas com problemas existenciais, crises, angústias,
depressões... muitas vezes por problemas financeiros, conjugais, de relações
familiares. Houve também uma demanda enorme das escolas municipais, estaduais e
até da rede privada, para atender as crianças que tinham problemas de
aprendizagem... Então teve... assim... uma explosão de demanda. Além disso, os
hospitais não fizeram uma adesão ao projeto de mandar os egressos de uma maneira 
sistematizada, com fluxo definido. Os internos dos hospitais, quando melhoravam, na maioria das vezes, não eram encaminhados para a atenção básica (FRANCISCA).

Analisando esse relativo fracasso das ações em saúde mental na atenção primária, Silva (2013) defende que ele pode ser explicado pelo fato de serem elas algumas ações em saúde mental "periféricas, em relação às engrenagens que moviam a verdadeira 'indústria da loucura' que movimentava milhões em interesses nos recursos públicos previdenciários" (SILVA, 2013, p. 02). Foi nessa conjuntura de desmonte da política de saúde mental provocado pelo reacionário governo de Newton Cardoso e da constatação da não-eficiência das ações do Programa de Saúde Mental que Minas Gerais começou a se preparar para participar, em 1987, da I Conferência Nacional de Saúde Mental (I CNSM). Tal Conferência foi convocada para debater, entre outros temas, “A Reforma Sanitária e a reorganização da assistência à saúde mental” (BRASIL, 1988, p. 09).

Realizada como etapa preparatória para a Conferência Nacional, a I Conferência Estadual de Saúde Mental de Minas Gerais (I CESM/MG) tornou-se um espaço bastante rico para se debater as questões relativas à necessidade de se empreender um redirecionamento na política de saúde mental do Estado. Como abordado há alguns parágrafos, as iniciativas empreendidas pelos trabalhadores de saúde mental mineiros não obtiveram o êxito desejado; inúmeros militantes tinham sido depostos de seus estratégicos cargos públicos; as ações em saúde mental na atenção primária não se fizeram suficientes para barrar as internações hospitalares. Tampouco as ações desenvolvidas dentro dos manicômios lograram êxito, levando à constatação de que não seria possível humanizar/domesticar o hospício. Todo esse contexto acabou por intensificar as críticas ao modelo assistencial tradicional e colocou em cheque as próprias estratégias utilizadas até então pelos trabalhadores da saúde mental do Estado. Desse modo, a convocação da I CNSM, com o propósito de reformular todo o modelo assistencial em saúde mental, ecoou com grande força no território mineiro.

Para além desses elementos, a I CESM/MG foi o espaço que possibilitou o encontro de duas gerações dos militantes da saúde mental de Minas Gerais, "a geração dos antigos militantes diretores dos hospitais psiquiátricos da FHEMIG nomeados pelos governos progressistas e demitidos pelo Newton Cardoso e a geração dos profissionais da atenção primária, contratada no concurso da FHEMIG” (ALBA). Esse encontro contribuiu de forma sensível para a consolidação do movimento dos trabalhadores em saúde mental de Minas Gerais, uma vez que reuniu militantes com origens e percursos profissionais bastante diferentes: alguns com vasta experiência de trabalho e de militância exercidos dentro do hospital psiquiátrico; outros, com experiência profissional e militância fora dos domínios dos 
hospitais (LOBOSQUE, 1997). Ambos os grupos com forte desejo de contribuir para a alteração dos rumos da assistência em saúde mental vigente até então, e dispostos a unir forças na luta para tal.

Em síntese, foram elementos como 1) a insatisfação dos profissionais com o tipo de condução antidemocrática da política de saúde mental dada pelo governo de Newton Cardoso; 2) a constatação dos limites existentes na estratégia de militar a partir do aparelho do Estado; 3) a comprovação, a partir da própria prática profissional, da impossibilidade de domesticar/humanizar o hospital psiquiátrico; e 4) a complexificação do caldo cultural e político propiciado pelo encontro das duas gerações de militantes na I Conferência Estadual de Saúde Mental - fortalecendo os militantes mineiros - que constituíram a efervescente conjuntura política sob a qual Minas Gerais elegeu sua delegação para representar o Estado na I Conferência Nacional de Saúde Mental.

Durante a I CNSM, alguns delegados militantes do Movimento dos Trabalhadores em Saúde Mental (MTSM) realizaram reuniões paralelas às oficiais, nas quais constataram que não seria mais possível o Movimento continuar se diluindo dentro da máquina estatal (AMARANTE, 1998). Nessas mesmas reuniões, debateram a necessidade de se empreender uma reorganização política e estratégica do Movimento em função do erro cometido (de se misturar ao Estado) e propuseram a realização de um evento nacional - o Congresso de Bauru - objetivando reorganizar a ação política do MTSM. Destaca-se que, tanto nas reuniões paralelas de reflexão acerca dos rumos do MTSM realizadas durante a I CNSM, quanto na comissão encarregada de organizar o Congresso de Bauru, Minas Gerais se fez presente com trabalhadores representantes das duas gerações de militantes já mencionadas anteriormente.

Segundo a depoente que concedeu a primeira entrevista, a comissão encarregada de preparar o encontro nacional em Bauru/SP contou com representantes do Rio de Janeiro, de Minas Gerais, de São Paulo, do Espírito Santo e de Goiás. No caso da Comissão de Minas, ela era composta por Marcus Vinícius de Oliveira Silva - militante da 'nova geração' - e Cezar Rodrigues Campos e Wellerson Alkimim - militantes da 'velha geração'. Um mês antes do encontro de Bauru, a comissão mineira promoveu um encontro estadual e foi criado o Fórum Permanente de Saúde Mental de Minas Gerais (ALBA).

Assim, tanto em Minas Gerais, quanto em outros Estados, o processo preparatório para a I CNSM foi importantíssimo para a problematização da situação da assistência em saúde mental como um todo, bem como para a consolidação do ideal antimanicomial que viria a ser proposto em Bauru. 


\section{2 - A consolidação do Movimento Mineiro de Trabalhadores de Saúde Mental}

Os trabalhadores da saúde mental militantes presentes no Congresso de Bauru retornaram para Minas Gerais, sem, entretanto, contar com um grupo ou um núcleo antimanicomial dotado de uma organicidade. Uma razão para isso era que as então recentes ideias e ideais originários no Congresso de Bauru ainda não haviam se propagado pelo Estado. O próprio Fórum Permanente de Saúde Mental de Minas Gerais, recém-criado com o objetivo inicial de propiciar as discussões preparatórias para o encontro de Bauru, não se constituía ainda como um grupo solidificado. Nestes termos, diz um depoente: "nós éramos um grupo, mas como qualquer coletivo. Vem gente, vai gente... Uns ficam, outros não ficam... O certo é que alguns de nós nos mantivemos [...]. O Fórum seguiu, com alguns encontros" (FRANCISCA).

Assim sendo, à época, esse grupo ainda não possuía uma linha estratégica de luta ou uma agenda de ações políticas. Além da ausência de agenda, da instabilidade de frequentadores e irregularidade na periodicidade com que os encontros ocorriam, o Fórum Permanente de Saúde Mental de Minas Gerais não contava com um lugar fixo para realizar suas reuniões, como informam as autoras dos depoimentos a seguir: "Nós fizemos um encontro que aconteceu na Associação Médica [...] A gente se encontrava lá no auditório do Santo Agostinho. [...] A gente se reuniu no auditório da FUMEC e no CRP” (FRANCISCA). “O CRP sediou alguns encontros do Fórum” (ALBA).

Apesar dessa relativa falta de organicidade predominante naqueles tempos, em Minas Gerais, o ideal antimanicomial construído a partir do Congresso de Bauru foi sustentado, nos seus primeiros anos, pelo Fórum Permanente de Saúde Mental de Minas Gerais, contando com o apoio da Associação Mineira de Psiquiatria e do Conselho Regional de Psicologia (ALBA).

Como registrado acima, o Congresso de Bauru inaugurou, no país, a luta antimanicomial. A complexidade dessa empreitada fez com que o movimento pela reorientação da saúde mental no Brasil adotasse, a partir de então, novos referenciais teóricos e diferentes rumos políticos em relação ao que vinha sendo praticado até 1987. Uma das propostas de modificações empreendidas pelo Movimento Antimanicomial, à época, foi deixar de ser um movimento exclusivo de técnicos e trabalhadores da saúde mental, para se aproximar e abarcar outros atores sociais, como os usuários dos serviços de saúde mental e seus familiares; além de fazer alianças com movimentos sociais de outros setores da sociedade (AMARANTE, 1998). 
Em Minas Gerais, difundir o ideal antimanicomial para os diversos grupos sociais não se configurou em uma tarefa fácil. Isso porque, ao regressarem de Bauru, os trabalhadores militantes antimanicomiais mineiros se depararam com uma sociedade que mantinha intacta a mesma cultura manicomiocêntrica que possuía antes de 1987. Belo Horizonte, por exemplo, "como outras capitais mais desenvolvidas, vinha caminhando na direção de uma cultura manicomial solidamente implantada" (LOBOSQUE e ABOU-YD, 1998, p. 243).

A bandeira: Por uma sociedade sem manicômios! bem como a definição de um dia nacional para se celebrar a luta antimanicomial, instituídos no Congresso de Bauru, se revelaram como estratégias extremamente importantes para o Movimento, uma vez que se tornaram referências agregadoras para a militância. Assim, os trabalhadores mineiros iniciaram, já em 1988, suas ações, na tentativa de colocar em prática os princípios antimanicomiais, os quais, por sua vez, buscavam desconstruir o paradigma assistencial fundamentado na tutela e segregação social bem como problematizar junto à sociedade novas formas de se lidar com a loucura e com a pessoa do louco. Fiéis às diretrizes traçadas no Congresso de Bauru, os militantes de então buscaram, inicialmente, empreender ações que seguissem "um caminho de alargamento das fronteiras da luta para uma ação no interior da própria cultura, trazendo a discussão sobre a loucura para o cotidiano da sociedade, numa estratégia que ampliava a atividade puramente assistencial" (NETO, 2008, p. 21). Assim, as ações dos militantes mineiros naqueles primeiros anos pós-Bauru, "tiveram um caráter mais demonstrativo, de lançamento das ideias antimanicomiais" (ALBA).

Neste contexto, as comemorações do dia 18 de maio iniciaram ancoradas em atividades culturais e reflexivas, cujo objetivo era propagar os preceitos da Reforma Psiquiátrica. As primeiras comemorações basearam-se na realização de entrevistas na mídia local, projeção de filmes temáticos com posterior debate a respeito, realização de oficinas etc. "Nos primeiros tempos, os discursos, os pronunciamentos, enfim a formatação habitual dos atos públicos ainda marcavam formalmente os 18 de maio" (LOBOSQUE, 2001, p. 105). Nota-se que se tratou de atividades relativamente simples se comparadas às grandes manifestações públicas promovidas anos mais tarde e que perduram até os dias de hoje, com a participação de milhares de pessoas tanto de Belo Horizonte, quando do interior do Estado. Entre esses participantes, estão usuários, familiares, trabalhadores de saúde mental e adeptos em geral à causa antimanicomial.

Nos anos que se seguiram (1989, 1990, 1991 e 1992), ocorreram importantes eventos que contribuíram para a consolidação do Movimento Nacional Antimanicomial. Os impactos desses acontecimentos se fizeram sentir também em Minas Gerais. Desse modo, no plano 
jurídico, foi apresentado ao Congresso Nacional o Projeto de Lei Antimanicomial n. ${ }^{\circ}$ 3657/89, de autoria do Deputado Federal PT/MG Paulo Delgado e foram promulgadas também as leis 8080/90 e 8142/90, ambas de regulamentação do Sistema Único de Saúde (SUS). No âmbito assistencial, houve a paradigmática e exitosa intervenção na Casa de Saúde Anchieta, em Santos/SP, provando ser exequível a ideia de substituição do hospício por outros serviços de saúde mais abertos. Contou-se, também, com a implantação do SUS, causando forte impacto na descentralização da saúde, através da municipalização dessa política. No aspecto político, as eleições municipais de 1988 e 1992 colocaram no poder candidatos - vereadores e prefeitos - originários de partidos democráticos/populares, sobretudo do Partido dos Trabalhadores, que à época despontava como uma nova opção oposicionista. Também em 1992, realizaram-se a IX Conferência Nacional de Saúde e a II Conferência Nacional de Saúde Mental.

Além desses eventos mencionados, outros acontecimentos em nível local também impactaram positivamente as diversas políticas públicas, entre elas a de saúde mental. Tal situação causou rebatimentos favoráveis sobre a atuação do Movimento Antimanicomial Mineiro. Dentre esses eventos, cabe citar: 1) em 1989 - início do processo de municipalização e descentralização dos serviços de saúde na capital de Minas Gerais; 2) em 1990 promulgação da Lei Orgânica do Município de Belo Horizonte, a qual estabeleceu possibilidades de criação de instâncias de participação popular; realização da II Conferência Municipal de Saúde 3) no ano de 1991 - criação da lei que regulamentou a criação do Conselho Municipal de Saúde de Belo Horizonte, dos Conselhos distritais e dos Conselhos locais, além da Conferência Municipal de Saúde. Foi também em 1991 que se encerrou a reacionária administração do governo de Newton Cardoso, com a posse de Hélio Garcia no governo do Estado. Nesse mesmo ano, ocorreu a III Conferência Municipal de Saúde de Belo Horizonte e a II Conferência Estadual de Saúde de Minas Gerais. Ainda em 1991, foi realizada uma auditoria técnica em todos os hospitais psiquiátricos do Estado, e foi também viabilizado o contato dos trabalhadores de saúde mental mineiros com a experiência de Santos. Em 1992, houve a elaboração do Projeto de Lei antimanicomial de Minas Gerais e, também neste ano, o Partido dos Trabalhadores elegeu seus candidatos em diversos municípios mineiros, entre eles, Belo Horizonte.

Essa sucessão de eventos políticos e sociais colaborou de forma significativa para que se buscasse uma consolidação da democracia tal qual estava prevista pela Constituição Federal de 1988. Desse modo, a Carta Magna - ao fortalecer as comunidades locais, ampliando-lhes a capacidade deliberativa sobre a condução das políticas públicas - favoreceu 
o surgimento de iniciativas criativas no âmbito da saúde mental, por parte de diversos municípios mineiros. Além disso, a democratização das relações entre o Estado e a Sociedade Civil pós-1988, possibilitou aos movimentos sociais um envolvimento nos mecanismos participativos recentemente implantados.

Foi essa conjuntura sociopolítica constituída na virada da década de 1980 para a de 1990 que possibilitou a diversos municípios do interior de Minas Gerais - Brumadinho, Betim, Itaúna, João Monlevade, dentre outros - a criação de serviços de saúde mental, levando em consideração os preceitos da Reforma Psiquiátrica brasileira (LOBOSQUE, 1997). Desse modo, por iniciativa dos trabalhadores de saúde mental de várias cidades de Minas, realizou-se em 1991, em João Monlevade, o I Encontro Mineiro de Trabalhadores de Saúde Mental.

Destaque interessante, e que precisa ser mencionado neste ponto do estudo aqui apresentado, está na constatação de que, nesse momento da trajetória aqui reconstruída, o nome Fórum Permanente de Saúde Mental de Minas Gerais desaparece dos registros orais e escritos coletados para a composição deste texto. Ao mesmo tempo, os registros referentes ao Movimento Antimanicomial de Minas Gerais passam a adotar a expressão Movimento Mineiro de Trabalhadores de Saúde Mental.

Mesmo sem dados que possam alimentar uma afirmação assertiva das razões desse acontecimento ou que permitam afirmar se e por que ocorreu a dissolução do Fórum Permanente de Saúde Mental de Minas Gerais, arrisca-se a elaboração de duas hipóteses a respeito do desaparecimento de uma expressão e o surgimento da outra. A primeira é que houve a fusão dos dois grupos, uma vez que o número de militantes em comum era muito grande, não justificando a existência de encontros separados. A segunda hipótese refere-se à supremacia do nome oriundo do I Encontro Mineiro de Trabalhadores de Saúde Mental, uma vez que essa nomenclatura era mais adequada para expressar a composição desse coletivo. Isso porque, naquela ocasião, como afirma Lobosque (1997, p. 56), “o movimento se reduzia ainda ao enunciado do seu nome: Movimento Mineiro de Trabalhadores de Saúde Mental”. Ou seja, era um coletivo fundamentalmente composto por trabalhadores, não contando com a participação efetiva dos usuários de serviços de saúde mental e seus familiares. 


\section{3 - Do Movimento Mineiro dos Trabalhadores de Saúde Mental ao Fórum Mineiro de Saúde Mental: um percurso}

\section{1 - A descentralização da assistência em saúde em Belo Horizonte}

No âmbito da política federal, o Partido dos Trabalhadores (PT) foi derrotado nas urnas em 1989 por Fernando Collor de Melo, do partido da Reconstrução Nacional (PRN) candidato conservador e alinhado com a Direita. Os anos que se seguiram foram marcados por comprovações de uma série de denúncias de irregularidades, bem como um grande esquema de corrupção envolvendo o Presidente, culminando com a retirada de Collor da Presidência da República. Nesse contexto, instaurou-se, no país, certa decepção da população em relação ao Estado e com seus governantes conservadores, contribuindo, assim, para que candidaturas populares crescessem pelo Brasil. Todo esse contexto corroborou para que nas eleições desenvolvidas a partir de então, em um quadro de multipartidarismo, ganharam destaque os partidos políticos vinculados a uma linha mais popular/progressista.

Em Minas Gerais, essa tendência da conjuntura política nacional pôde ser observada no nível municipal, onde as eleições de 1992 ocorreram sob o impacto das grandes manifestações populares na campanha Fora Collor, situação que beneficiou sobremaneira os partidos de esquerda. Desse modo, apesar de, no âmbito federal, o país ter vivenciado um contexto político conservador, diversas administrações municipais e estaduais foram assumidas por partidos políticos progressistas, como foi o caso de Betim e de Belo Horizonte.

Os governos progressistas que assumiram os inúmeros municípios nos quais foram eleitos enfrentaram o desafio de pôr em prática uma gestão democrática/popular, associando elementos da democracia representativa com alguns de democracia participativa. Fez-se necessário materializar, no cotidiano da gestão pública, um sistema político descentralizado, cujos canais de participação popular no controle social do Estado passaram a garantir o envolvimento da Sociedade Civil organizada nos processos de tomada de decisão do Estado.

Alguns anos antes, em 1988, a Constituição Federal havia instituído um modelo de gestão estatal mais democrático e mais participativo criando assim, mecanismos formais de descentralização político-administrativos, além de canais institucionalizados de participação popular. Naturalmente, a operacionalização desses mecanismos não se deu de forma tranquila e sem resistências. Isso porque, para colocar em prática o novo modelo de gestão pública, era preciso desconstruir a cultura autoritária e centralizadora da política brasileira vigente até então, a qual sempre manteve a Sociedade Civil subordinada ao Estado, concentrado neste o poder de decisão político e administrativo acerca das políticas públicas. 
Além desses entraves da cultura política brasileira marcada pelo autoritarismo da relação do Estado com a Sociedade Civil, havia ainda o desfavorável cenário econômico brasileiro vigente à época, marcado pelo discurso neoliberal, preconizando a diminuição da responsabilidade do Estado para com as diversas políticas públicas.

Sob esse cenário, a implantação do Sistema Único de Saúde representou um enorme desafio para os governos municipais comprometidos com a gestão democrática, uma vez que um dos princípios deste Sistema era a descentralização política, administrativa e assistencial, atribuindo ao município a responsabilidade para com a execução de ações na área da saúde.

A abertura do espaço para a participação popular, bem como a estruturação dos serviços e ações em saúde de forma descentralizada, regionalizada e hierarquizada então postas para os municípios eram francamente defendidas pelo Movimento Mineiro de Trabalhadores de Saúde Mental. Isso porque os princípios da luta pela extinção do manicômio estavam absolutamente alinhados com os princípios e diretrizes do Sistema Único de Saúde, sobretudo com a ideia de descentralização da assistência em saúde mental que, à época, estava predominantemente centrada no hospital psiquiátrico. Nos depoimentos a seguir, verifica-se esta posição a favor do SUS e seus princípios: "A gente tinha uma posição clara de defesa da saúde pública e de um sistema único de saúde [...], a ligação do Movimento Antimanicomial com a defesa dos princípios do SUS sempre foi muito visceral” (RENATA). "A Reforma Psiquiátrica no Brasil só foi possível porque existiu o SUS. Eu não tenho nenhuma dúvida e falo isso publicamente! A Reforma só foi possível por meio da ideia da saúde pública, uma saúde de lógica territorial, universal" (GISELE).

Nota-se, assim, que todas as mudanças políticas e sociais ocorridas no âmbito da saúde no Brasil, desde a década de 1970, atingiram, também, o campo da saúde mental. A partir do início da década de 1980, algumas iniciativas em saúde mental do governo federal propunham conter as internações psiquiátricas hospitalares por meio de uma ambulatorização da assistência. De todas essas iniciativas, a mais avançada foi a implantação - no âmbito da saúde geral - das Ações Integradas de Saúde (AIS). Tal avanço pôde ser percebido em Minas Gerais, através da expressiva ampliação dos serviços ambulatoriais a partir de 1985 (GOULART, 1992). Apesar disso, mesmo que o Programa de Saúde Mental de Minas Gerais tenha derivado das AIS e implicado em importantes modificações na assistência à saúde mental no Estado, ele esbarrou, à época, em limites estruturais e políticos. Episódios dessa ordem, evidenciam, portanto, que nem todo o avanço na concepção de saúde e da maneira de gerir a sua administração e sua assistência trazidos pelo SUS conseguiu, de imediato, deslocar 
a posição central que o hospital psiquiátrico representava no atendimento à pessoa com transtorno mental.

\section{2 - A auditoria técnica nos hospitais psiquiátricos em Minas Gerais}

No plano estadual, a administração de Hélio Garcia, iniciada em 1991 "devolveu um mínimo de liberdade de ação aos trabalhadores de saúde mental” (LOBOSQUE, 1997, p. 55). Naquela ocasião, graças às atuações do Movimento Mineiro de Trabalhadores de Saúde Mental o ideal antimanicomial havia se espalhado pelos mais diversos setores das Sociedades Civil e Política, ganhando tanto adeptos quanto adversários. Nestes termos, a Coordenação Estadual de Saúde Mental daquela época, comungando dos preceitos da Reforma Psiquiátrica, teve a iniciativa de promover uma auditoria em todos os hospitais psiquiátricos existentes em Minas Gerais. Auditoria esta que objetivava mapear a real situação da rede hospitalar existente no Estado, conhecendo o número exato de internos e as condições de tratamento a que estavam submetidos. Foi a primeira vez que o governo de Minas Gerais promoveu uma 'devassa' nos hospitais psiquiátricos, com a participação ativa dos trabalhadores da saúde mental. O depoimento abaixo descreve como se deu essa auditoria:

A auditoria foi uma iniciativa, a princípio, das pessoas que então estavam na Coordenação de Saúde Mental do Estado de Minas Gerais que eram a Gisele Bahia e o Abílio. [...] E então qual era a proposta? Era que a gente passasse pelos trinta e seis hospitais existentes na época em todo Estado, totalizando 8.000 leitos. Estes hospitais estavam concentrados, sobretudo, em Belo Horizonte, Juiz de Fora e Barbacena, mas também havia alguns em outros municípios. Pretendia-se - e assim foi feito! - que a gente examinasse um por um dos 8 mil internos, utilizando questionários preparados previamente, para verificar diagnóstico, história, tempo de internação, necessidade ou não da internação, etc. Isso exigiu uma força de trabalho enorme. A gente fazia grandes caravanas, que viajavam em um ou dois ônibus, Minas afora. Éramos todos trabalhadores de saúde mental, porque, apesar de ter um objetivo político, eram avaliações segundo critérios técnicos. Então, a gente fazia uma caravana que ficava três dias em Juiz de Fora, até entrevistar todos os pacientes de lá. Na semana seguinte íamos ficávamos mais três dias em Barbacena, e assim em todos os municípios onde houvesse hospitais psiquiátricos. Isso tudo era pago, financiado pelo Estado: o transporte, a estadia... a própria autorização para entrar nos hospitais provinha do governo Estadual. Isso foi uma iniciativa totalmente inédita. Existiam supervisores, teoricamente responsáveis pelo único tipo de fiscalização que existia nos hospitais - mas este cargo era apenas formal, uma espécie de sinecura. [...] Então foi realmente uma iniciativa inédita porque nós, do Movimento dos Trabalhadores de Saúde Mental nunca tínhamos podido entrar nestes hospitais. [...] Então, no final desse processo, que durou alguns meses, nós conseguimos examinar os oito mil pacientes dos trinta e seis hospitais então existentes em Minas [...] (RENATA).

O Movimento Mineiro dos Trabalhadores de Saúde Mental já se encontrava, a essa época, constituído como um movimento organizado e bastante combativo, com capacidade de 
intervir nas políticas municipais e estaduais de saúde mental (LOBOSQUE, 1997; LOBOSQUE e ABOU-YD, 1998). Assim sendo, essa auditoria se revelou como uma prova da capacidade de influência do Movimento Mineiro em colaborar com a condução da política de saúde mental. Isso porque, como visto no depoimento acima, a dedicação dos trabalhadores de saúde mental - a maioria deles, senão todos, era de integrantes do Movimento - foi fundamental para exequibilidade das visitas. Além disso, um militante em particular - Cezar Rodrigues Campos ${ }^{\mathrm{i}}$-, um dos líderes do Movimento Mineiro dos Trabalhadores de Saúde Mental, exerceu papel fundamental na aglutinação dos técnicos que participaram daquela ação.

A conotação política da auditoria e o receio quanto ao que ela poderia revelar causaram resistência de alguns segmentos da sociedade, sem, contudo, fazer com que ela fosse interrompida. O diagnóstico situacional resultante da conclusão da auditoria nos hospitais mineiros revelou uma situação calamitosa de maus tratos, péssimas condições estruturais das instituições e graves violações aos direitos humanos dos internos. Contudo, foi “a constatação da existência de um enorme número de internações cuja manutenção não se justificava tecnicamente que revelou-se em um dado que fortaleceu politicamente ainda mais luta antimanicomial" (RENATA). Assim, os dados revelados trouxeram à luz aspectos dos hospitais psiquiátricos que já vinham sendo denunciados desde o III Congresso Mineiro de Psiquiatria em 1979. Nestes termos, constatar, em 1991, que os hospitais mineiros continuavam cumprindo o seu papel higienista de abrigar pessoas abandonadas por suas famílias e excluídas pela/da sociedade, garantindo lucros aos seus proprietários com a manutenção de internações desnecessárias, aumentou a convicção do Movimento Mineiro de Trabalhadores de Saúde Mental em se posicionar frontalmente contra a existência dessas instituições.

Foi nesse contexto que se impôs um dilema para a política de saúde mental em Minas Gerais, uma vez que estava mais que evidente a falência do modelo hospitalar enquanto proposta terapêutica, mas, ao mesmo tempo, a proposta de atendimento ambulatorial não tinha demonstrado a eficácia esperada. Assim, o dilema mineiro se instaurou na medida em que o próprio poder público e o Movimento Mineiro de Trabalhadores de Saúde Mental, apesar de se darem "conta dos limites do ambulatório como alternativa, desconheciam na prática outras experiências, como os núcleos de atenção psicossocial (Naps), os centros de convivência, as pensões protegidas" (LOBOSQUE, 1997, p. 55). 


\section{3 - O contato com a experiência antimanicomial de Santos}

O dilema referido no tópico anterior terminou por motivar "a Coordenação da Secretaria Municipal de Saúde, em 1991, a conhecer o projeto de saúde mental [...] da cidade de Santos (SP), governada pelo Partido dos Trabalhadores" (PEREIRA, 2004, p. 290). A visita a Santos foi apoiada e patrocinada pela Fundação Hospitalar do Estado de Minas Gerais. À época, a única experiência exitosa de fechamento de uma unidade hospitalar e sua consequente substituição por uma rede de serviços de saúde mental diversificada - que ia muito além de meros ambulatórios - era a da cidade do interior de São Paulo. O contato com a experiência de Santos é assim relatado por uma depoente:

A ida a Santos foi extremamente marcante para cada um de nós. [...] Já tinha
passado o período de fechamento do Anchieta e os pacientes já estavam todos nos
NAPS, mas vamos chamar de CAPS que é o nome oficial. CAPS territorializados e
abertos. [...] Santos é muito inspirado em Trieste, inclusive do ponto de vista teórico.
Então, para a gente, foi realmente uma descoberta, uma revelação surpreendente.
Principalmente por ver que aqueles CAPS abrigavam pacientes muito graves, para
os quais, pra nossa cabeça daquela época, a gente pensaria numa internação a curto
prazo. Mas eles eram mantidos ali em serviços abertos, cuidados em liberdade! [...]
Nós visitamos todos os CAPS, visitamos os Centros de Convivência. [...]. Foi muito
interessante a gente cruzar, nos CAPS, com aqueles mesmos tipos de paciente que
aqui em Belo Horizonte estavam internados. Foi interessante participar de
assembleias com eles, quer dizer, ver uma relação muito mais democrática, ver o
jeito com que a equipe lidava com o paciente, com uma proximidade tanto física
quanto afetiva que não existe no hospital psiquiátrico por 'melhor' que ele seja [...].
Então, essa visita a Santos nos deu não só essa certeza de que a gente podia
dispensar o recurso hospital psiquiátrico [...], como também nos mostrou
concretamente como isso era feito e que isso já era feito. Quer dizer, não era uma
ideia que jamais foi posta em prática. Era uma ideia que já estava sendo
concretamente executada lá no município de Santos (RENATA).

Pelo que se percebe neste trecho, a oportunidade de conhecer a Experiência de Santos representou um marco para as pessoas envolvidas com a causa antimanicomial em Minas Gerais, apresentando-lhes a possibilidade de superar o dilema da saúde mental. Ou seja, "nem ambulatórios, nem hospitais, porém serviços territorializados, capacitados para o acolhimento de paciente em crise" (LOBOSQUE, 1997, p. 56). Assim, para os trabalhadores de saúde mental, foi possível conhecer outras práticas baseadas em uma lógica de atendimento bastante diferente daquela que eles estavam acostumados. Para os gestores, ficou provado ser possível aplicar aquela política também nos municípios de Minas Gerais. Já para o Movimento Mineiro dos Trabalhadores de Saúde Mental, o contato com Santos revelou-se um marco decisivo, mostrando ser exequível a proposta antimanicomial defendida pelo Movimento. 


\section{4 - A Lei da Reforma Psiquiátrica de Minas Gerais}

No campo jurídico, o já mencionado Projeto de Lei Federal n. 3657/89, embora ainda estivesse em tramitação no Congresso Nacional sob acirrada disputas políticas, havia desencadeado, em Minas Gerais, debates e discussões sobre a necessidade de reorientação da assistência em saúde mental. Somando-se a isso, o ano de 1992 foi um ano em que todo o país estava se preparando para a IX Conferência Nacional de Saúde e para a II Conferência Nacional de Saúde Mental. Além disso, foi também em 1992 que ocorreram as disputas eleitorais municipais que se desenvolveram sob a efervescência política causada pelos debates em torno do processo de impeachment do presidente Fernando Collor de Melo.

Sob essa conjuntura sociopolítica, o Movimento Mineiro dos Trabalhadores de Saúde Mental, cada vez mais amadurecido e combativo em função dos últimos acontecimentos e experiências vivenciados, buscou traçar uma agenda política para fortalecer sua luta. $\mathrm{O}$ Movimento Mineiro resolveu elaborar um projeto de Lei Antimanicomial para Minas Gerais, usufruindo de alianças feitas com outros segmentos da sociedade e iniciando um diálogo com deputados estaduais objetivando elaborar tal Projeto. Assim sendo, o conteúdo do Projeto ficou a cargo exclusivo do Movimento, cabendo aos parlamentares oferecerem suporte técnico e jurídico. Sob o número 1.066/92, o Projeto deu entrada na casa legislativa estadual, onde tramitou durante três anos. Durante essa tramitação, foram realizadas inúmeras reuniões para ouvir os segmentos interessados (ALVIM, 1996).

De fato, apesar de ter sido submetido a inúmeras reuniões públicas para a discussão acerca do seu conteúdo, bem como enfrentar diversos questionamentos sobre sua proposta por alguns segmentos sociais e ter passado por várias Comissões e pelo Plenário da Assembleia, o Projeto de Lei 1.066/92 recebeu a totalidade dos votos a seu favor, sendo aprovado sem modificações substanciais no seu texto. Nestes termos, o Projeto se transformou na "Lei $n^{\circ}$ 11.802, de 1995, a Lei da Reforma Psiquiátrica de Minas, aprovada por unanimidade de votos pela Assembleia Legislativa, sancionada pelo governador e assinada também pelo secretário da saúde" (BARRETO, 1996, p. 60).

Embora tenha sido aprovado por unanimidade, o debate legislativo que se seguiu para a regulação da Lei 11.802/95 enfrentou fortes pressões de alguns grupos contrários à proposta. Tais grupos se articularam e se fizeram representar na Assembleia Legislativa para a defesa de seus interesses. Assim, durante o lapso de tempo que a Lei 11.802/95 aguardava para ser

regulamentada, foi dada a entrada, na Assembleia de Minas, de um outro Projeto de Lei $n^{\circ}$ 
576/95, o qual propunha redefinições na Lei da Reforma Psiquiátrica Mineira (ALVIM, 1996).

Os embates que se seguiram foram intensos, pois, os opositores da Lei reivindicavam importantes alterações no texto e, desta vez, estavam mais bem organizados e representados na Assembleia. Como ocorre em qualquer sociedade democrática, o processo que se formou em torno dos embates dos grupos favoráveis e dos adversários à Lei Mineira foi delimitado pelo jogo de forças sociais presentes em cada lado. Com o ideal antimanicomial bastante disseminado na sociedade mineira, com o Movimento Antimanicomial consolidado e com o favorável contexto político da época, a Lei 11.802/92 "sofreu algumas emendas em 1997, que não interferiram, contudo, na essência do seu texto" (MINAS GERAIS, 2007, p. 32). Em síntese, o lado favorável à luta antimanicomial saiu em vantagem no embate. A esse respeito, importante constatação é feita por uma entrevistada, quando ela avalia os desdobramentos da Lei da Reforma Psiquiátrica mineira para além de sua função de instrumento legal: “[...] Essas leis fazem um marco jurídico que abre um precedente político e simbólico enorme. Então, quando a gente conseguiu aprovar a Lei Carlão, a gente ganhou um terreno enorme no debate aqui em Minas. A gente ficou muito empoderado (RENATA).

\section{5 - Os usuários e os familiares no Movimento Antimanicomial Mineiro}

No âmbito nacional, a II Conferência Nacional de Saúde Mental (II CNSM) foi realizada em 1992, antecedida por um amplo processo de mobilização social que contou em expressiva participação de usuários de serviços de saúde mental e de seus familiares. A própria coordenação do evento tinha, entre seus integrantes, grupos organizados de usuários e familiares. O Movimento Mineiro de Trabalhadores em Saúde Mental se fez presente na II CNSM e isso possibilitou o contato entre os militantes mineiros com outros grupos antimanicomiais organizados. Nesse contato, chamou a atenção de alguns militantes de Minas Gerais a diversidade de composição dos outros grupos, isto é, a não exclusividade de trabalhadores. Sobre isso, assim relata uma entrevistada: "Nós fomos à segunda Conferência Nacional de Saúde Mental, e foi nessa Conferência que nós vimos que o Rio Grande do Sul já estava muito mais avançado. Eles já tinham uma Lei aprovada e eles já estavam junto dos usuários" (FRANCISCA).

É interessante observar que o adjetivo 'avançado', atribuído ao grupo do Rio Grande do Sul, pauta-se não só na referência à lei antimanicomial que aquele Estado já tinha aprovada, mas também, pelo fato de o Movimento Gaúcho já contar com a participação dos 
usuários dos serviços de saúde mental. Cabe lembrar, que a lei antimanicomial mineira naquele dezembro de 1992 - já se encontrava em tramitação na Assembleia Legislativa de Minas Gerais. Os militantes usuários, porém, ainda teriam que aguardar para fazer parte da realidade do movimento de Minas (LOBOSQUE, 1997).

Vasconcelos (2006, p. 26) afirma que “a II Conferência Nacional de Saúde Mental foi um marco na história da psiquiatria brasileira e abriu um novo caminho para a consolidação da Reforma Psiquiátrica do país”. De fato, o legado deixado pela II CNSM foi muito valioso. Para Minas Gerais, além de todo o direcionamento para uma política de saúde mental radicalmente antimanicomial apontado pela II CNSM, a participação ativa, na qualidade de militantes políticos, dos usuários dos serviços de saúde mental também foi um aprendizado, como se nota neste depoimento: "Depois que nós fomos na II Conferência de Saúde Mental e vimos que tinha usuários nos grupos, voltamos para cá e começamos a discutir isso com os pacientes do hospital Raul Soares, porque era lá que tinha pacientes no hospital-dia" (FRANCISCA).

Outra entrevistada afirma que o Movimento Mineiro de Trabalhadores de Saúde Mental sempre desenvolveu ações de defesa dos direitos de cidadania das pessoas com transtorno mental (RENATA). Nesse sentido, sempre que necessário, o Movimento tomava posição quando, por exemplo, havia alguma violação de direitos humanos dos usuários. Na medida em que a luta antimanicomial foi exigindo do Movimento uma militância mais constante e mais organizada para fazer grandes enfrentamentos como, por exemplo, no processo de defesa da Lei da Reforma Psiquiátrica de Minas, iniciava-se também uma maior preocupação com a participação dos usuários e dos familiares. A mesma depoente destaca também que a ampliação da participação dos usuários se deu, ao longo do tempo, tanto de forma quantitativa, quanto qualitativa. "No próprio movimento nacional sempre teve um usuário ou outro. Eram usuários que tinham uma formação, às vezes universitária e que ficavam muito no registro da testemunha, do depoimento. Depois, o número foi aumentado e a qualidade da participação também" (RENATA).

Com o tempo, destaca a entrevistada, a participação dos usuários e dos familiares foi se tornando mais politizada e mais atuante. Neste contexto, o ano de 1993, ou seja, alguns meses depois da II CNSM, ficou marcado com a efetiva participação e o engajamento dos usuários e de familiares no Movimento Antimanicomial de Minas Gerais. Assim, a delegação antimanicomial mineira que foi para o I Encontro Nacional da Luta Antimanicomial, em Salvador/BA, contou com a representação tanto dos usuários quanto de seus familiares, conforme destaca o depoimento a seguir: “[...] Quando nós fomos para 
Salvador no Primeiro Encontro do Movimento Antimanicomial em 1993, a delegação que foi era a metade de usuários e metade de trabalhadores. [...] Esse encontro foi o momento mais significativo em que eles [usuários] agiram como atores políticos de fato, participando dos grupos de discussão" (RENATA).

\section{6 - A influência do Movimento Mineiro dos Trabalhadores de Saúde Mental sobre a política de saúde mental de Belo Horizonte na gestão pública de 1993 a 1996}

A coligação partidária denominada Frente BH Popular elegeu, em 1992, o candidato do Partido dos Trabalhadores (PT), Patrus Ananias de Souza, para prefeito de Belo Horizonte. "A população participou ativamente e de forma nunca vista em prol do candidato majoritário e dos vereadores de esquerda pretendentes à Câmara Municipal” (PEREIRA, 2004, p. 319). Por isso, a expectativa nos projetos e propostas desse governo, no que se referia às políticas sociais, era muito grande.

Sem objetivar enaltecer as práticas e intenções administrativas de um partido político, chama a atenção o fato de que as condições para a participação popular no controle social - ao menos nos discursos e no texto legal - estavam dadas no Brasil em função de uma conjuntura sociopolítica e cultural forjada ao longo de muito embate entre o Estado e a Sociedade Civil, sobretudo durante o processo de redemocratização política nos anos de 1980. No caso de Belo Horizonte, e especificamente no campo da saúde mental, de fato a relação entre Poder Público e Sociedade Civil se configurou de forma democrática no governo de Patrus Ananias. Nestes termos, aberto ao diálogo com diversos movimentos sociais progressistas - entre eles o Movimento Mineiro dos Trabalhadores de Saúde Mental - o governo municipal acolheu a proposta de política de saúde mental elaborada pelo Movimento. Sobre isso, Pereira, (2004, p. 319), considera que "tal coletivo teve uma influência decisiva no programa de saúde mental da prefeitura petista, entre os períodos de 1993 e 1996, em Belo Horizonte”. O autor ainda acrescenta que a política de saúde mental implantada à época pautou-se por "diretrizes que foram inspiradas a partir dos ideários do Movimento Mineiro dos Trabalhadores de Saúde Mental" (PEREIRA, 2004, p. 319).

Assim, o projeto de saúde mental então proposto estava completamente alinhado com os preceitos do SUS e com as recomendações advindas da IX Conferência Nacional de Saúde e da II Conferência Nacional de Saúde Mental. De todas as diretrizes e princípios desses grandes documentos, talvez o mais enfatizado pelo projeto de saúde mental tenha sido a municipalização e a descentralização da assistência em saúde. Nestes termos, usufruindo da 
abertura ao diálogo expresso pela gestão do PT com os mais variados segmentos sociais, os trabalhadores realizaram assembleias para eleger nomes a serem sugeridos à administração, visando o preenchimento de cargos de gestão em setores específicos. No caso da saúde, tanto o nome indicado pelo funcionalismo para ocupar os importantes cargos de chefia na secretaria de saúde, quanto na coordenação de saúde mental, foram acatados pelo governo municipal. Assim, Cezar Rodrigues Campos foi nomeado Secretário Municipal de Saúde, e Miriam Nadin Abou-yd, nomeada Coordenadora Municipal de Saúde Mental, sendo que ambos eram pessoas engajadas há muito tempo no movimento pela luta antimanicomial em Minas Gerais.

\section{7 - A constituição jurídica do Fórum Mineiro de Saúde Mental}

Como visto, desde o Congresso de Bauru, em 1987, diversos grupos antimanicomiais se formaram pelo país. Entretanto, era característico desses núcleos não terem uma organicidade, uma formalização e organização interna. No caso do núcleo antimanicomial mineiro, não foi diferente. Foram cerca de cinco anos de caminhada para que o núcleo mineiro se constituísse como um Movimento Antimanicomial combativo, cujas principais características eram: ter uma agenda política própria; possuir experiência e acúmulo de ações antimanicomiais bem-sucedidas no plano jurídico, na dimensão da assistência e na defesa dos direitos humanos das pessoas com transtorno mental; ter clareza do seu papel no controle social das ações do Estado no tocante à política de saúde mental; possuir uma organização consolidada e independente de entidades de classes ou de categorias profissionais; ter real capacidade de influenciar a política pública de saúde mental. Entretanto, apesar de todas essas características, o Movimento Mineiro de Trabalhadores de Saúde Mental, embora já tivesse descoberto a importância de se contar com a participação dos usuários e familiares e já soubesse da necessidade de dialogar com outros núcleos antimanicomiais, além de não contar “com uma participação efetiva dos usuários, [...] mantinha-se isolado nas fronteiras de Minas desconectado das articulações nacionais. Em 1993, um único passo permitiu transpor esta dupla barreira: o I Encontro Nacional da Luta Antimanicomial” (LOBOSQUE, 1997, p. 56). De fato, o I Encontro Nacional da Luta Antimanicomial, realizado em 1993, foi planejado para propiciar um espaço em que todos os núcleos antimanicomiais do país pudessem se reunir, trocando experiências e vivências de suas práticas de luta. Assim, ao participar desse evento, foi possível ao Movimento Mineiro tanto conhecer e aprender com outros grupos, como ocorreu na II Conferência Nacional de Saúde Mental, como também socializar sua história e suas próprias experiências, servindo de referência para outros núcleos. Além disso, 
o I Encontro Nacional da Luta Antimanicomial marcou o abandono completo do tecnicismo e se abriu à participação efetiva dos usuários e familiares. Esse último aspecto aumentou a convicção do Movimento mineiro em ampliar a possibilidade de participação dos usuários, bem como colaborar com a organização destes (LOBOSQUE, 1997).

Na plenária final do Encontro, a delegação mineira presente foi eleita pela assembleia para ocupar a Secretaria Executiva Nacional do Movimento. Essa responsabilidade de secretariar nacionalmente o Movimento Antimanicomial "foi então partilhada com os usuários, que passam a assumir, uma função de liderança. Assim, um movimento que sofreu por várias vezes as tentações do tecnicismo e dos riscos do isolamento, vem consolidar sua verdadeira vocação de um movimento social” (LOBOSQUE, 1997, p. 56).

A conquista dessa posição de liderança da Secretaria Executiva do Movimento Nacional passou a exigir do Movimento mineiro - ator político, solidamente organizado e com alguns anos de caminhada na luta antimanicomial - uma constituição jurídica e formal. A partir de então, no início do ano de 1994, o nome oficial do movimento antimanicomial de Minas Gerais passou a ser conhecido como Fórum Mineiro de Saúde Mental, um coletivo constituído predominantemente por familiares e usuários dos serviços de saúde mental, bem como por trabalhadores desses serviços. Desde então, esse coletivo “organiza-se como um movimento social, sendo ainda um laboratório no qual se criam projetos, ações, estratégias e intervenções que dão corpo à utopia antimanicomial” (CASTRO, 2008, p. 222), estando há vinte e dois anos nesse empreendimento.

\section{Considerações finais}

Na reflexão aqui apresentada, constatou-se que tanto o Fórum Permanente de Saúde Mental de Minas Gerais, quanto o Movimento Mineiro dos Trabalhadores de Saúde Mental (MMTSM) - precursores do FMSM - emergiram influenciado pelas mudanças teóricas e políticas que vinham ocorrendo no Movimento Nacional da Luta Antimanicomial. Isso porque, os elementos norteadores das discussões e questionamentos acerca da política pública de saúde mental em Minas Gerais, no período de 1987 até 1994, estavam totalmente alinhados com os preceitos do movimento nacional pela Reforma Psiquiátrica.

Estritamente ligado a esse primeiro, o segundo fator que constituiu as condições de emergência do FMSM foi a conjuntura política democrática vivenciada pelo Estado de Minas Gerais no início dos anos 1990. Tal contexto político, aliado ao fortalecimento dos municípios por meio da descentralização fiscal e administrativa favoreceu, - não só Belo Horizonte, mas 
também algumas cidades do interior do Estado -, o surgimento das primeiras iniciativas em saúde mental, tendo como referência outros serviços que não a internação em hospital psiquiátrico. Nestes termos, a disseminação das práticas antimanicomiais pelas cidades de Minas Gerais, juntamente com o progresso das diversas ações em saúde mental, favoráveis à Reforma Psiquiátrica e encabeçadas pela gestão estadual democrática, configuraram-se em elementos que reverberaram positivamente sobre o então MMTSM. Isso favoreceu a consolidação do Movimento, caracterizando-o como combativo, possuidor de agenda política própria, detentor de autonomia em relação ao Estado, enfim capaz de fazer proposições e de influenciar a formulação da política pública de saúde mental local, bem como exercer o controle social sobre a mesma.

Um terceiro fator determinante para a emergência do FMSM foi o fato de o MMTSM reconhecer a necessidade de mudança na posição do usuário no processo de luta pela política de saúde mental, retirando-o de sua mera posição de espectador e colocando-o na condição de ator político que também faz o movimento acontecer. Isso fez com que o Movimento Mineiro seguisse, mais uma vez a tendência nacional e rompesse com um tecnicismo e com um isolamento interno, possibilitando o diálogo com outros atores sociais, sobretudo aqueles mais interessados na causa da saúde mental: os seus usuários.

Assim, alinhado com o pensamento de Gohn (2004) quando esta autora afirma que o surgimento de um movimento social na perspectiva da ação coletiva depende de um conjunto de fatores, que alinhados, constituem a sua formação, o presente trabalho mostrou que foram os fatores acima mencionados que, juntos multideterminaram as condições de emergência do FMSM. Sem se manter isolado e imune aos efeitos da conjuntura política, social, econômica e cultural do período aqui enfocado; e sendo forjado em um processo complexo de aceitação e de resistências, o Fórum Mineiro de Saúde Mental se materializou em Minas Gerais, pretendendo tornar as aspirações antimanicomiais uma realidade no Estado.

\title{
ORIGINS OF FÓRUM MINEIRO DE SAÚDE MENTAL: A STUDY ON THE CONDITIONS OF EMERGENCY OF A ANTI-ASYLUM SOCIAL MOVEMENT
}

\begin{abstract}
This article aims to identify and systematize the emergency conditions of the Forum Mineiro de Saúde Mental, considering political, social and economic aspects occurred between the years 1987 and 1994, and identifying its effects, influences and reverberations about the formation of FMSM. Therefore, the investigation has combined information from oral sources, written and documentary about panel of social, political, economic and cultural events of the conjuncture of Minas Gerais in which emerged the Fórum Mineiro de Saúde Mental. All this reflecting in a perspective of conjunctural analyses. It was found that the
\end{abstract}


FMSM did not remain isolated and immune to the effects of political, social, economic and cultural period here focused. Therefore, forged in a complex process of acceptances and resistances, the Fórum Mineiro de Saúde Mental was materialized in Minas Gerais, intending to make into reality the anti-asylum aspirations in the state.

Keywords: movement against asyluns. psychiatric reform. social movement.

\title{
ORÍGENES DE LO FÓRUM MINEIRO DE SAÚDE MENTAL: UN ESTUDIO SOBRE LAS CONDICIONES DE EMERGENCIA DE UN MOVIMIENTO SOCIAL ANTIMANICOMIAL
}

\begin{abstract}
Resumen
Este artículo tiene como objetivo identificar y sistematizar las condiciones de emergência de lo Fórum Mineiro de Saúde Mental, teniendo en cuenta los aspectos políticos, sociales y económicos que se produjeron entre los años 1987 y 1994, y la identificación de sus efectos, influencias y repercusiones en la formación de FMSM. Con este fin, la investigación ha combinado la información de fuentes orales, escritas y documental sobre panel de eventos sociales, entorno político, económico y cultural en el que la minería ha surgido Fórum Mineiro de Saúde Mental. Todo esto se refleja en una perspectiva de análisis conyuntura. Se encontró que el FMSM no permaneció aislado o inmune a los efectos del período político, social, económico y cultural que aquí se centraron. Así forjada en un complejo proceso de aceptación y resistencia, El Fórum Mineiro de Saúde Mental se materializó en Minas Gerais, con la intención de hacer antimanicomiais aspiraciones sean una realidad en el estado.
\end{abstract}

Palabras clave: movimiento anti-asilo. reforma psiquiátrica. movimientos sociales.

\section{Referências}

ALVIM, L. T. Lei Carlão na berlinda. Revista do Legislativo. Belo Horizonte, v. 14, p. 57-59. 1996.

AMARANTE, P. Loucos pela vida: a trajetória da reforma psiquiátrica no Brasil. 2. ed. Rio de Janeiro: Fiocruz. 1998.

ARBEX, D. O holocausto brasileiro: vida, genocídio e 60 mil mortes no maior hospício do Brasil. São Paulo: Geração Editorial. 2013.

BRASIL, M. S. I Conferência Nacional de Saúde Mental: relatório final. Brasília: Centro de documentação do Ministério da Saúde. 1998.

CASTRO, A. M. Fórum Mineiro de Saúde Mental: a alegria e a coragem de se fazer política. Em K. Nilo e outros (Orgs.). Política de saúde mental de Belo Horizonte: o cotidiano de uma utopia (pp. 221-227). Belo Horizonte: Secretaria Municipal de Saúde de Belo Horizonte. 2008.

GOHN, M. G. Teoria dos Movimentos sociais: Paradigmas clássicos e contemporâneos. 4. ed. São Paulo: Loyola. 2004. 
GOULART, M. S. B. O ambulatório de saúde mental em questão: desafios do novo e reprodução de velhas fórmulas. Belo Horizonte. 197f. Dissertação de Mestrado. Programa de Estudos Pós-Graduados em Sociologia, FAFICH, UFMG, Belo Horizonte, MG. 1992.

Cezar Rodrigues Campos: de psiquiatra a militante da Reforma. Em ANAIS DO I ENCONTRO DE PESQUISADORES EM HISTÓRIA DA SAÚDE MENTAL. 2001. Florianópolis: Centro de Filosofia e Ciências Humanas da UFSC. p. 46-51. 2001.

LOBOSQUE, A. Princípios para uma clínica antimanicomial e outros escritos. São Paulo: Hucitec. 1997.

Experiências da loucura. Rio de Janeiro: Garamond. 2001.

LOBOSQUE, A. \& ABOU-YD, M. A cidade e a Loucura - entrelaces. Em C. R. Campos e outros (Orgs.). Sistema Único de Saúde de Belo Horizonte: reescrevendo o público (pp. 243264). São Paulo: Xamã. 1998.

MINAS GERAIS. Linha guia de Atenção em Saúde Mental. 2 ed. Belo Horizonte. 2007.

NETO, J. L. F. Psicologia e Saúde Mental: três momentos de uma história. Saúde em Debate Rio de Janeiro, v. 32, p. 18-26. 1998. Disponível em http://www.saudeemdebate.org.br /edicoes/index.php 1998 Acesso: em 14 de outubro de 2014.

PEREIRA, W. O adoecer psíquico do subproletariado: projeto de saúde mental na comunidade. Rio de Janeiro: Imago. 2004.

SILVA, M. V. O. Sobre as origens da luta antimanicomial. Belo Horizonte, Mimeo. 2013.

SOUZA, M. E. Os movimentos sociais - organização política dos usuários em saúde mental rompendo preconceitos e expandindo a vida: outros segmentos da sociedade civil organizada. Belo Horizonte. 175f. Dissertação de Mestrado, Programa de Estudos Pós-Graduados em Saúde Pública, Faculdade de Medicina, Universidade Federal de Minas Gerais. 2002.

VASCONCELOS, E. M. Breve periodização do processo de reforma psiquiátrica no Brasil recente. Em E. M. Vasconcelos (Org.). Saúde mental e serviço social: o desafio da subjetividade e da interdisciplinaridade (pp. 19-34). São Paulo: Cortez. 2006.

Dispositivos associativos de luta e empoderamento de usuários, familiares e trabalhadores em saúde mental no Brasil. Revista de Antropologia Vivência. Natal/RN, v. 32, p. 173-206. Disponível em http://www.cchla.ufrn.br/Vivencia/publicados layout.html 2007. Acessado em 21 de outubro de 2014.

Reforma psiquiátrica no Brasil: periodização histórica e principais desafios na conjuntura atual. Em E. M. Vasconcelos (Org.). Abordagem psicossociais, volume II: reforma psiquiátrica e saúde mental na ótica da cultura e das lutas populares. p. 27-55. São Paulo: Hucitec. 2008.

\footnotetext{
i Cézar Rodrigues Campos foi um dos principais organizadores e articuladores do III Congresso Mineiro de Psiquiatria (1979). Foi coordenador de saúde mental da Fundação Hospitalar do Estado de Minas Gerais. Participou ativamente da I Conferência Nacional de Saúde Mental (1987). Foi militante do Movimento de Luta Antimanicomial, desde 1987. No período de 1993 a 1996 foi Secretário Municipal de Saúde na prefeitura de Belo Horizonte na gestão de Patrus Ananias de Souza.
} 
Data de recebimento: 02/10/15

Data de aceite: $24 / 01 / 17$

\section{Sobre os autores:}

Ronaldo Alves Duarte é Doutorando em Política Social pela Universidade Federal Fluminense. Mestre em Política Social pela Universidade Federal Fluminense (2014). Mestre em Educação, Cultura e Organizações Sociais pela FUNEDI-UEMG (2008). Especialista em Saúde Mental: Família e Comunidade pela Pontifícia Universidade Católica de Minas Gerais (2004) e Bacharel em Serviço Social pela Pontifícia Universidade Católica de Minas Gerais (2002). Atualmente é efetivo no Serviço de Referência em Saúde Mental - SERSAM Divinópolis. É professor com experiência de mais de oito anos no magistério na área de Serviço Social, com ênfase em Políticas Sociais, Movimentos Sociais, Políticas Públicas relacionadas à saúde, saúde mental e família. Endereço Eletrônico: ronaldosocial1@gmail.com 